\title{
VALIDATION OF ONTARIO'S NEW LABORATORY-BASED BIOACCUMULATION METHODS WITH IN SITU FIELD DATA
}

\author{
Jordana L. Van Geest, ${ }^{*} \dagger$ David G. Poirier, $\ddagger$ Paul K. Sibley, $\nmid$ and Keith R. Solomon $\dagger$ \\ $\dagger$ University of Guelph, Guelph, Ontario, Canada \\ $\ddagger$ Ontario Ministry of the Environment, Etobicoke, Ontario, Canada
}

(Submitted 26 July 2010; Returned for Revision 29 August 2010; Accepted 18 November 2010)

\begin{abstract}
To validate the standardization of a laboratory protocol for measuring bioaccumulation, laboratory-derived tissue residues and biota-sediment accumulation factors (BSAFs) were compared with historical field data from nine sites in Ontario, Canada. As a result of temporal discontinuity between the field and the laboratory studies, a priori considerations, such as changes in site conditions or concentrations of contaminants in sediment, were necessary to assess whether to compare absolute or relative measures of bioaccumulation. For the majority of sites, BSAFs for field-collected and laboratory-exposed fish were within a factor of 2 . Biotasediment accumulation factors for laboratory-exposed oligochaetes were typically greater than those for mussels caged in the field, by a factor of 2 to 9 . Overall, the laboratory methods for all species generally overestimated the relative bioavailability of contaminants compared with field conditions by a factor of 1.1 to 9.2. Other than the great disparity observed for polychlorinated dibenzo- $p$-dioxins and dibenzofurans (PCDD/Fs) between field and laboratory studies, on average the laboratory-derived BSAFs with Pimephales promelas and Lumbriculus variegatus overestimated those from field-collected fish and field-exposed mussels by factors of 1.6 and 3.6 , respectively. The laboratory method reflects a potentially worst-case exposure scenario and provides an appropriately conservative estimate of bioaccumulation. Laboratory-based estimates can be comparable to bioaccumulation data from the field but may be confounded by species-specific differences in routes of exposure and bioaccumulation of certain compounds or other environmental and biological factors that should be considered in these comparisons. Environ. Toxicol. Chem. 2011;30:950-958. (C) 2011 SETAC
\end{abstract}

Keywords-Bioaccumulation Sediment Field validation Laboratory methods

\section{INTRODUCTION}

For many years, ecological risk assessment of contaminated sediments was based on three lines of evidence: sediment chemistry, toxicity testing, and benthic surveys. However, the assessment of the potential for bioaccumulation and/or biomagnification of contaminants has been identified as crucial to this process $[1,2]$ and is now an important and routine part of environmental assessments [3,4]. Several approaches are available for determining the bioaccumulation of contaminants in biota, which includes field monitoring, laboratory tests, and the use of models. Each approach has both applications and limitations based on the stage of the risk assessment, the questions being addressed, and the level of certainty required.

The most direct and ecologically relevant approach to assessing bioaccumulation is to measure concentrations of contaminants in the tissue of organisms collected or exposed in the field [5]. Collection of young-of-the-year fish and sport fish has become an integral part of environmental monitoring programs, particularly within Ontario, Canada. However, the use of mobile and long-lived organisms may prove difficult for delineating zones of contamination or the effectiveness of remediation procedures. Sampling of benthic organisms, which provides a much clearer understanding of the bioavailability of contaminants and extent of contamination, is often limited by the workload constraints of obtaining sufficient tissue biomass for analytical measurements [5,6]. Caging organisms, such as freshwater mussels, in the field is one approach to address this

All Supplemental Data may be found in the online version of this article

* To whom correspondence may be addressed

(jvangees@uoguelph.ca).

Published online 20 January 2011 in Wiley Online Library

(wileyonlinelibrary.com). issue. Though providing a balance between experimental control and ecological relevance not offered with field collections or laboratory studies, in situ studies are still time-consuming, labor-intensive, and occasionally prone to vandalism, predation, or destruction $[7,8]$.

Compared with field studies, laboratory methods offer more flexibility with timing and typically reduce workload and cost as well as seasonal and spatial variability [7]. They allow control of environmental conditions and standardization of exposure techniques and test species used. They also allow research questions such as differences between species, kinetics of uptake, and fate of emerging contaminants of concern to be addressed as well as the integration of additional assessment endpoints such as survival, growth, and reproduction. Because organisms cannot avoid contaminants in a bioassay system, laboratory methods represent what is potentially a worst-case exposure scenario. Laboratory methods cannot completely replace or replicate field exposures but are intended to support field methods and/or fill data gaps. Although laboratory or fieldbased bioaccumulation data are frequently generated and applied on a site-specific basis, the use of standard methods enables contaminated sites to be compared with each other on a scientifically defensible basis and accurately ranked with respect to priority of clean-up and effectiveness of remediation.

In addition to the standardization of methods and approaches for assessing bioaccumulation, the U.S. Environmental Protection Agency [7] has also identified field validation of laboratory methods as a need with respect to sediment quality assessment. The Ontario Ministry of the Environment (OMOE) has recently completed development and standardization of a laboratory protocol for measuring bioaccumulation of sediment-based contaminants in freshwater organisms. This included an assessment of the bioaccumulation potential among test species, in 
which bioaccumulation from a variety of field-contaminated sediments was measured in the juvenile fathead minnow Pimephales promelas, the oligochaete Lumbriculus variegatus, and the mayfly nymph Hexagenia spp. [9]. However, field validation of these laboratory methods is necessary if quantitative estimates of exposure are to be used with confidence in ecological risk assessments and in making regulatory decisions.

In the present study, we compared both laboratory-derived tissue residues in fish and invertebrates and biota-sediment accumulation factors (BSAFs) with available field data (i.e., young-of-the-year fish or caged mussels) from nine sites in Ontario, collected as part of ongoing OMOE monitoring programs. We discuss the extent to which these laboratory methods reflect environmental exposures as individual case studies and in a general context to illustrate how they may be used to corroborate field investigations.

\section{MATERIALS AND METHODS}

\section{Laboratory and field bioaccumulation studies}

Sediments used in laboratory bioaccumulation tests were collected by staff of the OMOE from a variety of locations throughout Ontario between May, 2007, and July, 2008. Sites were chosen based on OMOE knowledge, historical monitoring of contamination (sediment and biota), and access to the sites. The sites were also chosen to represent a range in the type and degree of contamination (Table 1) and physical properties of sediment (see Table 1 of Van Geest et al. [9]).

All bioaccumulation tests were conducted between February and September, 2008, in the OMOE laboratory. Three test organisms (P. promelas, L. variegatus, and Hexagenia spp.) were exposed to sediment from each site for $28 \mathrm{~d}$ [based on $[10,11]]$ under static conditions, with continual aeration of overlying water [12-14]. Tests for each sediment were conducted using three replicates; with approximately $5 \mathrm{~g}$ (wet wt) of biomass per replicate for analysis of organic contaminants. Tissue residues of specific contaminants of concern were measured in unpurged organisms, because we considered this to be more ecologically relevant. Samples of control organisms were also analyzed on day 0 (preexposure) and day 28 for contaminants of concern and lipid content. Further details regarding test organisms, site codes, sample preparation, bioaccumulation tests, and physicochemical analyses are given by Van Geest et al. [9].
Field studies were conducted as part of independent investigations of the contaminated sites. This work occurred prior to the development and standardization of the new laboratory protocols for the OMOE and was the best available data for comparison of bioaccumulation between the laboratory and the field. The OMOE staff carried out the collection of sediment and fish and the caging of mussels in these field studies. Youngof-the-year fish were collected in late summer or early fall (August-October) and analyzed as individuals when possible ( $n=3-5$ per site). Freshwater mussels (Elliptio complanata), collected from a reference location (Balsam Lake, Ontario), were caged in the field for 21 or $28 \mathrm{~d}$. The field studies varied in terms of the number of mussels deployed and whether mussels were analyzed as individuals $(n=3$ per site) or a composite ( $n=1$ per site) of individuals $(n=4$ or $10-12)$. All physicochemical analyses of samples from field and laboratory studies were conducted by the Laboratory Services Branch of the OMOE, following their current standard operating procedures at the time of sample submission (see Van Geest et al. [9] for reference to relevant analytical procedures).

\section{Analysis of data}

Unless otherwise specified, all data reported are the sum of total congeners for polychlorinated biphenyls (PCBs) and polychlorinated dibenzo- $p$-dioxins and dibenzofurans (PCDD/Fs). For PCBs, data are the sum of total congeners measured with the method, with congener values below reporting limits treated as zero. For PCDD/Fs, data are the sum of total congeners measured with the method (limits of detection for congeners were not an issue for sites of concern). Contaminants of concern were measured at trace levels or below detection limits in preexposure (day 0) organisms, so corrections were not made to the day-28 concentrations measured in the tissue of laboratoryexposed organisms.

Concentrations of contaminants in tissue were normalized to lipid because of differences in lipid content between species, both within and between field and laboratory organisms. Biotasediment accumulation factors are a ratio of the concentration of a contaminant in tissue compared with the sediment and represent a relative measure of bioaccumulation. These factors were calculated for each species-contaminant-sediment combination, using concentrations in the tissue and sediment that were normalized to lipid and organic carbon content, respectively.

Table 1. Concentrations of the contaminants of concern between past and recent (2007-2008) sampling of the sites included in the present study as well as activities and changes that have occurred

\begin{tabular}{|c|c|c|c|c|c|}
\hline \multirow[b]{2}{*}{ Site } & \multirow[b]{2}{*}{ Contaminant of concern } & \multicolumn{3}{|c|}{ Concentration in sediment ${ }^{\mathrm{a}}$ (ng/g dry wt) } & \multirow[b]{2}{*}{ Activities or changes } \\
\hline & & Year & Historical & 2007-2008 & \\
\hline \multirow[t]{2}{*}{$\mathrm{BC}$} & $p, p$-DDD & 2004 & 140 & 300 & Excavation and potential release of \\
\hline & $p, p-\mathrm{DDE}$ & & 260 & 320 & upstream source in 2004 \\
\hline \multirow[t]{2}{*}{$\mathrm{CC}$} & $p, p$-DDD & 1995 & 220 & 150 & Clean-up of source on adjacent \\
\hline & $p, p$-DDE & & 69 & 93 & property \\
\hline K4 & PCB & 2002 & 210 & 400 & Dredged in 2005 \\
\hline LSJ & PCB & 2005 & 1,500 & 1,300 & None \\
\hline $\mathrm{LC}$ & PCB & 2003 & 58,000 & 58,000 & Industry closed/ceased discharge \\
\hline $\mathrm{SC}$ & PCB & 2006 & 3,500 & 340 & Excavation of sediment 2006-2007 \\
\hline TC & PCB & 2006 & 750 & 340 & None \\
\hline $\mathrm{UC}$ & PCB & 2005 & $430-4,700$ & 4,800 & Variable flow conditions \\
\hline $\mathrm{PC}$ & $\mathrm{PCDD} / \mathrm{F}$ & 2005 & 1.2 & 2.5 & Variable flow conditions \\
\hline
\end{tabular}

${ }^{a}$ Dichlorodiphenyldichloroethane (DDD) and dichlorodiphenyldichloroethylene (DDE) and sum of total congeners of polychlorinated biphenyls (PCBs) or polychlorinated dibenzo- $p$-dioxins and dibenzofurans (PCDD/Fs) measured with the method. 


\section{Comparisons between laboratory and field}

Our conceptual approach to the comparison of field and laboratory assessments and validation of the laboratory bioaccumulation protocol is outlined in Figure 1. Comparisons were made between similar types of organisms (fish to fish, invertebrates to invertebrates). Validation was achieved by comparing 2007-2008 sampling and laboratory data (sediment, tissue, BSAF) with historical field data collected by the OMOE between 1995 and 2006, depending on the site. In 2007 and 2008, sites were selected and sediments collected at various times based on sampler availability, and laboratory tests were conducted over eight months as part of the method development and comparison between species $[9,15]$. Our comparisons are therefore not based on samples collected at the same time or precisely the same place (except for site K4), although attempts were made in 2007 and 2008 to resample at the previous sites of the field studies. Simultaneous field collections or exposures would have required additional labor, site visits, organisms, and analytical resources. As a result, this approach required such a priori considerations as what activities had occurred at the site between sampling periods and whether site and sediment conditions had changed during this time (Table 1).

The laboratory- and field-derived estimates of bioaccumulation of the contaminants of concern for each site were based on analyses of individuals or composites of individuals, providing a mean estimate when possible. However, these do not represent discrete samples but are really subsamples describing the variability within the laboratory exposure (to one sediment sample) or caged exposure (one cage of mussels per site). For these reasons and the fact that comparisons are made across different species for the most part in different environments, we believed that statistical comparisons between laboratory- and field-based tissue residues and BSAFs were not appropriate.

Because of the number of site-specific comparisons that were possible, three sites were chosen to be discussed in detail as case studies. The sites were chosen because bioaccumulation data were available for both fish and invertebrates and were more representative of the different scenarios and outcomes of the conceptual approach in Figure 1. The two scenarios and three outcomes are as follows. If the concentrations of the contaminants of concern were similar (scenario 1) between sampling periods, direct comparison of tissue residues between field- and laboratory-exposed organisms was possible, and in

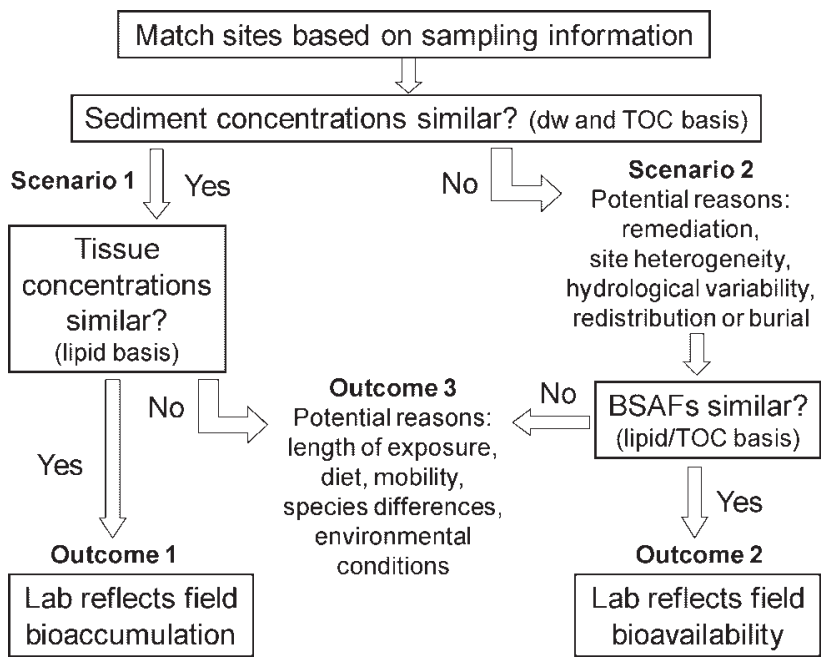

Fig. 1. Conceptual approach to the comparison of field and laboratory assessments of bioaccumulation. some cases tissue residues were similar (outcome 1). When the concentrations in sediment were not similar between sampling periods (scenario 2), the relative measures of bioaccumulation (BSAFs) were compared between field and laboratory studies. BSAFs were similar (outcome 2) in a number of these comparisons. The other outcome (3) was no agreement in the tissue residues or BSAFs between field and laboratory, regardless of whether sediment concentrations were similar between sampling periods. Those sites not considered in the case studies are discussed in terms of the overall trends between the field and the laboratory and the general context of scenarios and outcomes.

\section{RESULTS AND DISCUSSION}

Case study 1

The first site-specific example of a comparison between field and laboratory assessments of bioaccumulation is for site BC. This site was chosen because the organochlorine pesticide dichlorodiphenyltrichloroethane (DDT) and its metabolites dichlorodiphenyldichloroethane (DDD) and dichlorodiphenyldichloroethylene (DDE) were the contaminants of concern. Only DDD and DDE ( $p, p$-form) are discussed, because these metabolites were detected in all field- and laboratory-exposed organisms. On a dry weight basis, the concentrations of these contaminants in the sediment were greater in the 2008 than in the 2004 samples ( 2 and 1.2 times greater for DDD and DDE, respectively; Table 1). However, when normalized to organic carbon, the concentrations of DDD were the same between sampling periods (scenario 1), whereas DDE was approximately 1.7 times greater in the 2004 samples (partially scenario 2; Supplemental Data, Table S1). Concentrations of DDD in tissue were similar between field- and laboratoryexposed organisms (maximum difference 23\%; Fig. 2A), except in Hexagenia spp. nymphs, which accumulated significantly lower concentrations of DDD than the other laboratory-exposed organisms (also for site CC [9]). As a result of the similar concentrations in tissue and sediment, the BSAFs for DDD were also similar (within 25\%; Fig. 2B) between the field and laboratory (except for Hexagenia spp.). Differences in the tissue concentrations of DDE were observed between field- and laboratory-exposed organisms, even between species with a similar type of exposure (highest in field-collected fish, lowest in mussels; Fig. 2A). The BSAF for DDE in field-collected fathead minnows ( $P$. promelas) was 1.4 times higher than for fathead minnows exposed in the laboratory, thus partially accounting for potential differences in exposure. However, BSAFs for the laboratory-exposed invertebrates were two times higher than the BSAF for mussels. The BSAFs for the fish were approximately 4 to 5.5 times higher than for the field or laboratory invertebrate species. This case study demonstrates that laboratory methods can reflect bioaccumulation occurring under field conditions (outcome 1 with DDD, outcome 2 with DDE for fish) but that species-specific differences in bioaccumulation may exist and can vary between compounds.

\section{Case study 2}

Polychlorinated biphenyls (PCBs) were the contaminants of concern at site UC. Sampling of sediment throughout this site in 2005 found concentrations of PCBs of approximately 4,700 ng/ $\mathrm{g}$ dry weight, which is similar to the sediment concentration in the 2007-2008 sample. However, the location in site UC, where organisms were caged and collected in 2005, had a lower concentration in the sediment (only $430 \mathrm{ng} / \mathrm{g}$ dry wt) than in the 
A
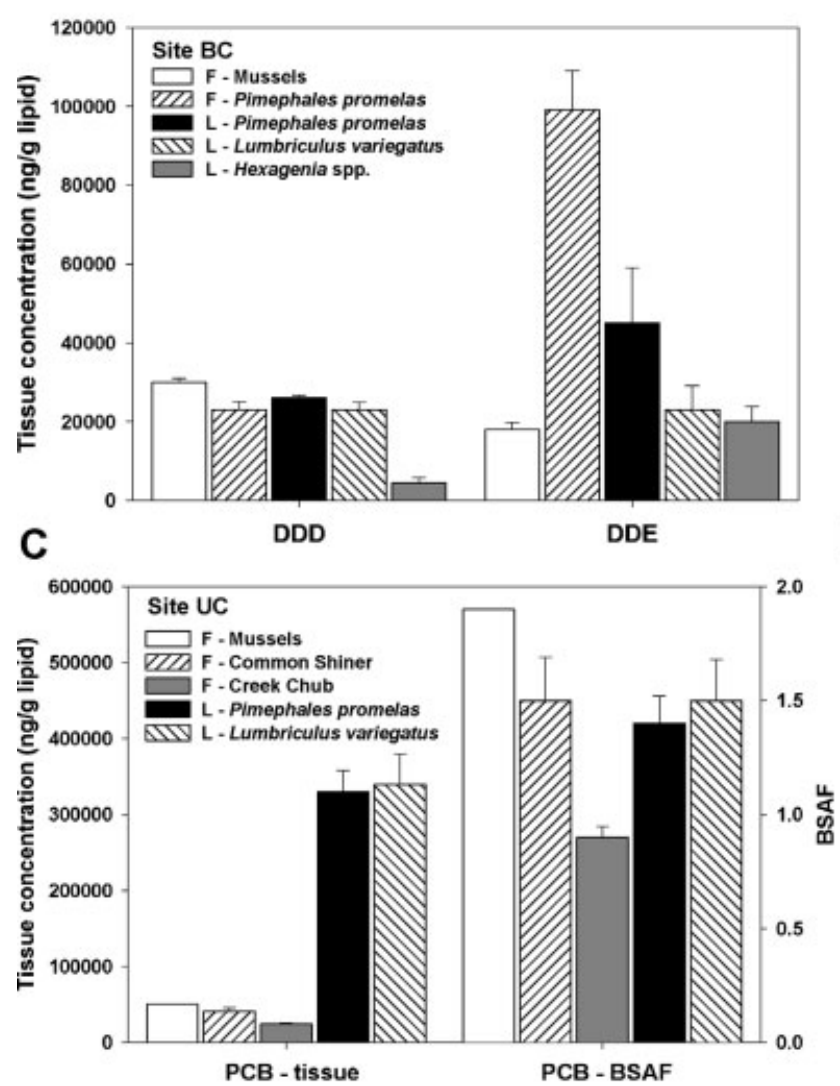

B
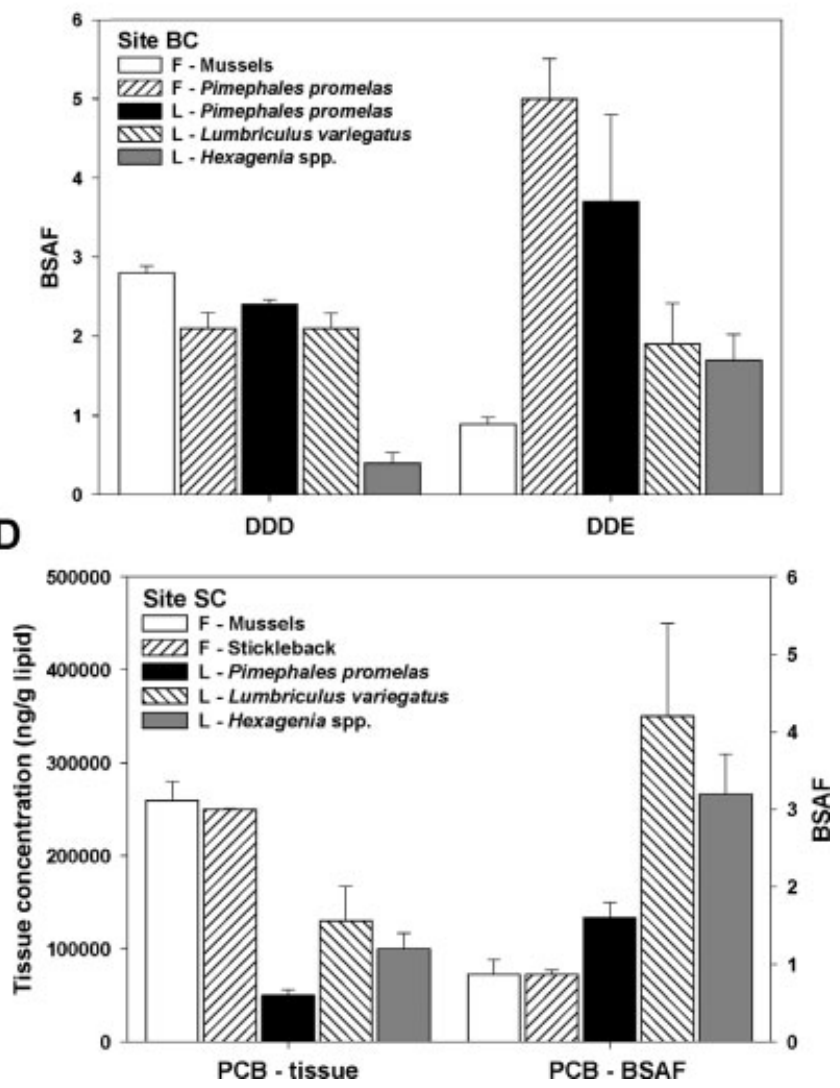

Fig. 2. (A-D) Concentrations in tissue and biota-sediment accumulation factors (BSAFs) of contaminants of concern in field (F)- and laboratory (L)-exposed organisms for sites BC, UC, and SC. BSAFs are normalized to lipid and organic carbon content of sediment. Data are mean and standard error (see Supplemental Data, Table S1, for $n$ ).

surrounding area. This demonstrates the potential for heterogeneity in contaminant distribution within a site. Variable flow conditions occurring at this site have the potential to form distinct depositional areas, resulting in this heterogeneity. In terms of bioaccumulation of PCBs from UC sediment, tissue concentrations were 7 to 14 times greater in laboratory-exposed organisms than those from the field (Fig. 2C), resulting from a tenfold difference in sediment concentrations (scenario 2). However, BSAFs for field- and laboratory-exposed organisms were within a similar range $(\mathrm{BSAF}=1.4-1.9$; Fig. $2 \mathrm{C})$, except for creek chub, in which bioaccumulation was slightly lower compared with the other organisms $(\mathrm{BSAF}=0.9)$. Overall, this suggests that the relative bioavailability of the PCBs was similar between field and laboratory exposures (outcome 2). However, even the field data demonstrate that differences in bioaccumulation between fish species may exist.

\section{Case study 3}

Polychlorinated biphenyls were also the contaminants of concern at site SC. This site was unique in the present study in that it had undergone extensive remediation involving excavation of sediment within the last few years. Between 2006 and 2007, a tenfold reduction occurred in the concentration of PCBs in the sediment that was sampled (Table 1; scenario 2). This difference in potential for exposure resulted in tissue concentrations of PCBs that were two to five times higher in fieldcollected or field-exposed organisms (2006) than in organisms exposed in the laboratory to the postremediation (2007) sediment (Fig. 2D). As a result of these relative differences being inconsistent, BSAFs were two times higher in laboratoryexposed fish and five times higher in laboratory-exposed invertebrates (Fig. 2D). This contrasts with equilibrium-partitioning theory, which assumes that BSAFs are independent of the concentration of the contaminant in the sediment [16,17]. A threshold may exist for the concentration of contaminants that can be accumulated, which could explain why the historic, field BSAFs are not as high as the more recent, laboratory BSAFs. Decreasing BSAFs with increasing concentrations of contaminants in sediment have been observed in field investigations of the bioaccumulation of PAHs [18] and PCDD/Fs [19] in benthic invertebrates, which was partially attributed to black carbon in the sediments. These differences in tissue residues and BSAFs between the field and the laboratory in the present study cannot be attributed to a change in the source of contamination because the profile pattern (\% contribution) of $\mathrm{PCB}$ congeners remained fairly similar within sediment and between field and laboratory organisms (data shown as PCB homologues in Supplemental Data, Fig. S1). Again, evidence of species-specific differences in the degree of bioaccumulation exists, but only in the laboratory organisms with the lower exposure concentrations. The high BSAFs of the laboratory-exposed invertebrates suggests that, despite the remediation efforts, the relative bioavailability of PCBs remaining at this site is still high. This example demonstrates a case in which, despite a major change in the concentration, but not the source, of contaminant in the sediment between sampling periods, a lack of agreement was noted in even relative measures of bioaccumulation (BSAFs) between the field and the laboratory (outcome 3 ). 


\section{Bioaccumulation comparison between field and laboratory fish}

The comparison of bioaccumulation between field-collected and laboratory-exposed fish is summarized for the nine sites in Figure 3A. This plot shows the ratio of tissue and sediment concentrations and BSAFs between field and laboratory studies. Points above the line (1:1 relationship) indicate that values were higher in the 2007-2008 laboratory studies, and points below that values were higher in the field studies. Presentation of the data in this manner clearly illustrates how the lack of agreement in the concentration of contaminants of concern in the tissue between field and laboratory fish may be associated with differences in the concentration in sediments. Comparison of BSAFs accounted for these differences in exposure, and, for the majority of sites, field- and laboratory-derived BSAFs were typically within a factor of 2 , despite the differences in time between the laboratory and the field studies.

For site K4, a 21-d laboratory exposure using fathead minnows [based on [12]] was conducted soon after sampling in the field in 2002 and showed very good agreement for concentrations in tissue and BSAFs between laboratory and field (factor of \pm 1.2 ), despite the fact that field-collected fish were mostly considered yearlings instead of young of the year.

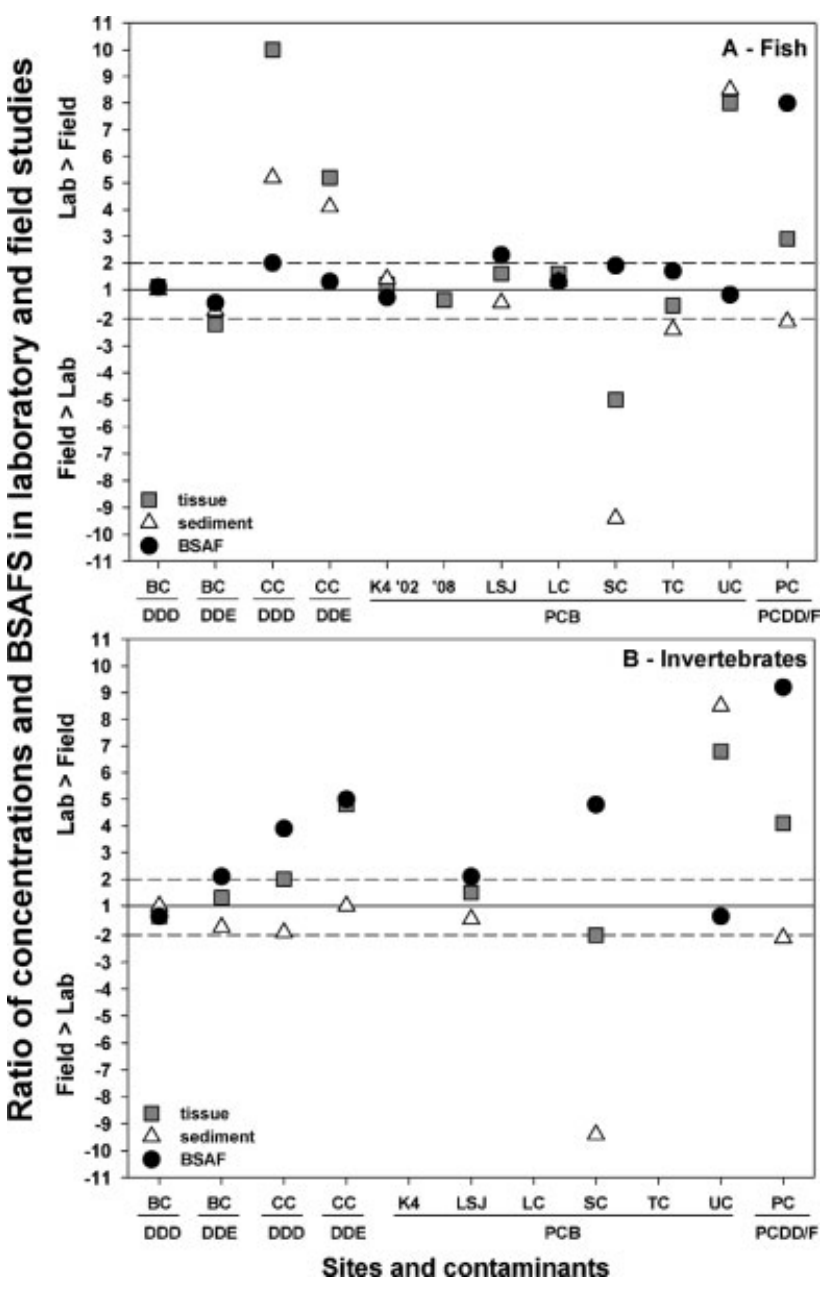

Fig. 3. Ratio of tissue and sediment concentrations and biota-sediment accumulation factors (BSAFs) in laboratory and field studies for various sites and contaminants of concern. (A) Pimephales promelas compared with young-of-the-year fish. (B) Lumbriculus variegatus compared with mussels. Concentrations are normalized to lipid and organic carbon content for tissue and sediment, respectively, including BSAFs.
In 2008, young-of-the-year fish were collected at site K4 within two months of collection of the sediment that was used in the 28-d bioaccumulation test. Again, concentrations in tissue were comparable between the field- and the laboratory-exposed fish (field 1.3 times higher than laboratory). This represents the ideal situation for validation of laboratory methods, insofar as temporal and spatial discontinuity are eliminated. What is interesting to note is that the bioavailability of PCBs at this site appears to have been reduced over this time, because, although concentrations of PCBs have not declined in the sediment, tissue residues and BSAFs in both field and laboratory fish had declined by factors of approximately 2 and 6 , respectively (Fig. 4 and Supplemental Data, Table S1).

In terms of the scenarios and outcomes in our approach to field and laboratory comparisons of the other sites, site CC fell under scenario 2 and was partially confounded by older sediment data (1995) and differences in sampling locations. However, BSAFs for DDD and DDE were only 1.3 to 2 times higher in the laboratory than field studies (outcome 2). Sites LSJ and LC fell under scenario 1 and site TC under scenario 2 in terms of comparability of sediment concentrations of PCBs. Concentrations in tissue were 1.6 times higher in laboratory-exposed fish than those from the field for sites LSJ and LC (outcome 1). The laboratory-derived BSAF for site TC was 1.3 times higher than that for the field (outcome 2).

The assessment of the bioaccumulation of polychlorinated dibenzo- $p$-dioxins and dibenzofurans (PCDD/Fs) from site PC shows greater disparity between field and laboratory studies. In laboratory-exposed fish, concentrations of PCDD/Fs in tissue were approximately three times higher and BSAFs eight times higher than for fish in the field. This disparity between the studies may be attributed to a number of factors, particularly, the heterogeneity of sediment parameters and variable flow conditions within the site. Differences existed between the sediment sampled in 2005 vs. 2007 to 2008, in that the earlier sample had not only a much lower concentration of PCDD/Fs ( $\sim 50 \%$ lower on a dry wt basis) but also a very low content of organic carbon $(<1 \%$; scenario 2$)$. When expressed on an organic carbon basis, this has the potential to skew the relative difference in concentrations between sediments (Supplemental Data, Table S1). The very low content of organic carbon may

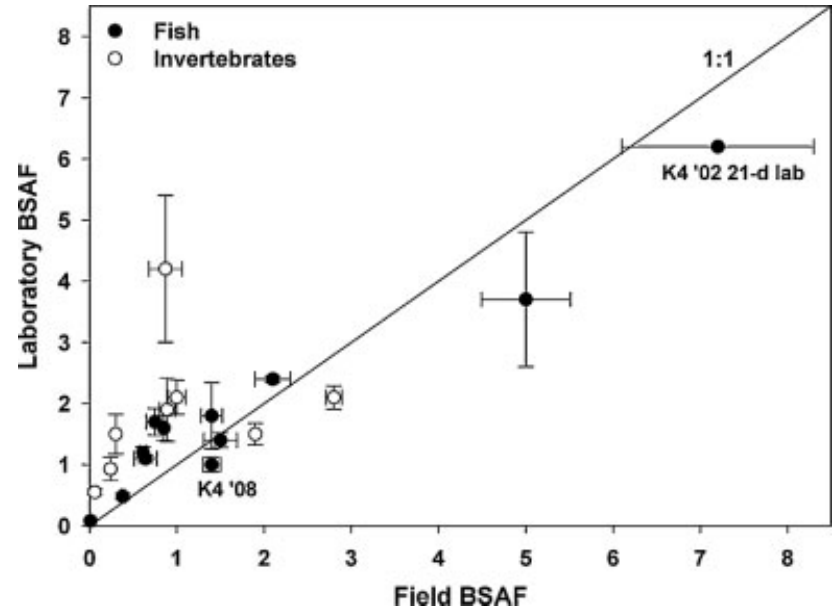

Fig. 4. Laboratory- versus field-derived biota-sediment accumulation factors (BSAFs) for fish (Pimephales promelas compared with young-ofthe-year) and invertebrates (Lumbriculus variegatus compared with mussels) in the present study. BSAFs are normalized to lipid and organic carbon content. Data are mean and standard error (see Supplemental Data, Table S1, for $n)$. 
influence not only the partitioning and distribution of contaminants but also the biological productivity in the area and therefore the presence and exposure of fish. Sampling throughout the area in 2005 revealed that the composition of sediment and concentrations of PCDD/Fs were highly variable within even a small area (OMOE, unpublished data). This heterogeneity of sediment at site PC and the disparity between estimates of bioaccumulation may be influenced by flow conditions, which are highly variable on an annual and seasonal basis, such that, at any given time, it may alter what sections of the creek bed are submerged and the access of fish to different areas (S. Petro, unpublished, OMOE, Etobicoke, Ontario, Canada, 2009). The result was that measures of bioaccumulation were not comparable between these field and laboratory studies (outcome 3). Apart from this site, the laboratory estimates of either absolute (tissue residues) or relative (BSAF) bioaccumulation in fish showed very good agreement with field estimates despite major differences such as duration of exposure, dietary sources, and mobility of fish in the field. Overall, the BSAFs determined with $P$. promelas in the laboratory overestimate those for fish collected in the field, on average, by a factor of 1.6 (2.4 if data from site PC are included).

\section{Bioaccumulation between field and laboratory invertebrates}

The differences in bioaccumulation between field- and laboratory-exposed invertebrates was summarized in a similar manner by plotting the ratios of the different parameters relative to a line equal to a $1: 1$ relationship (Fig. 3B). The ratios represent comparisons between laboratory-exposed oligochaetes (L. variegatus) and mussels (E. complanata) caged in the field. Fewer comparisons were made between invertebrates, because mussels were not caged at site K4, and the sediment from sites LC and TC was toxic to the other invertebrates when tested in the laboratory.

Unlike comparisons for the fish, the frequency and magnitude of differences between field- and laboratory-derived $\mathrm{BSAFs}$ were much greater for the invertebrates. For site CC, tissue residues of DDD and DDE were approximately two and five times higher, respectively, in L. variegatus than in the mussels, despite much smaller differences in concentrations between the sediment samples (partially scenario 2 for DDD and scenario 1 for DDE). This resulted in laboratory-derived BSAFs that were four to five times higher than field estimates (outcome 3). Lipid was not measured in the mussels caged at this site, so a lipid content of $0.8 \%$ was assumed based on typical values measured in the other field studies examined in the present study. Although the collection of young-of-the-year fish from site CC was more recent (2003), the sediment and mussel data presently available to the OMOE date back to 1995 . This case reflects what is both an atypical and a less than ideal comparison of bioaccumulation over time. For site LSJ, tissue concentration of PCBs was 1.5 times higher in L. variegatus than field-exposed mussels (outcome 1). Bioaccumulation of PCDD/Fs from site PC sediment was much higher in L. variegatus than in the mussels (outcome 3), with tissue concentrations and BSAFs that were approximately four and nine times higher, respectively. Overall, laboratory-derived BSAFs for L. variegatus were either similar to those of fieldexposed mussels (20-25\% difference) or then two to nine times higher. On average, the laboratory BSAFs overestimated those from the field by a factor of 3.6 (4.5 if data from site PC are included).

The potential for relative differences in exposure between these two invertebrates is much greater than for fish, because of the different feeding strategies and behavior of these organisms. Elliptio complanta are filter feeders and are exposed to contaminants via water and suspended sediment. Valve closure may also reduce exposure of mussels to contaminants. In contrast, $L$. variegatus actively burrow into and ingest sediment and are thus likely to have increased exposure to sedimentassociated contaminants. Comparison of bioaccumulation in species with different routes of exposure is not ideal, but the invertebrate data that were available. Collection of benthic invertebrates for tissue analysis is not a routine component of OMOE field studies. Regardless of this, often few or no invertebrates were observed in the collection areas during 2007 and 2008 (D. Poirier, personal observations) or in the sediment once processed in the laboratory (J. Van Geest, personal observations), which prevented any direct comparison between species that were more similar. Early attempts to expose field-collected mussels to sediments in the laboratory were unsuccessful because of the buildup of metabolic waste products (ammonia), so this species was not selected for the development of the laboratory methods. As previously suggested, species-specific differences in bioaccumulation may also exist and vary between contaminant and sediment, which can further complicate this type of laboratory and field comparison between different species.

\section{Comparison: Laboratory and field methods}

In the present study comparing bioaccumulation between the laboratory and the field, the laboratory methods described generally overestimated the bioavailability of contaminants compared with field conditions. That is, laboratory-derived BSAFs were often higher than the field estimates (Fig. 4). Although higher BSAFs from laboratory studies provide a more conservative estimate of bioaccumulation, it is important to identify and understand the sources of uncertainty that limit translation of data between the laboratory and the field.

The best approach for the validation of laboratory methods is to collect sediment from the contaminated site with the fieldcollected or field-exposed organisms and test in the laboratory as soon as possible (as with site K4). However, in many site investigations and risk assessments, field samples are collected over time as analytical data become available and the focus narrows to zones of contamination or hot spots, and temporal discontinuity of sampling is not uncommon. This potential for temporal variability was a major source of uncertainty for comparing field and laboratory data in the present study. Although the sites considered are historically contaminated with relatively persistent contaminants, the potential for changes at the sites was still considered by comparing chemical concentrations and congener profiles to assess whether it was appropriate to compare data between studies and in what manner (absolute vs. relative measures of bioaccumulation). Despite the temporal differences between field- and laboratorybased estimates of bioaccumulation, good agreement was observed between these studies for fish. However, reducing the influence of this potentially confounding factor will better facilitate comparisons between the laboratory and the field.

One source of uncertainty that can be quantified is the biological variability associated with bioaccumulation. High variability within and between field and laboratory estimates of bioaccumulation can contribute to the disparity between the two types of studies. Coefficients of variation $(\mathrm{CVs})$ for field- and laboratory-exposed organisms from the present study are shown in Figure 5 for the various sites and contaminants of concern. 


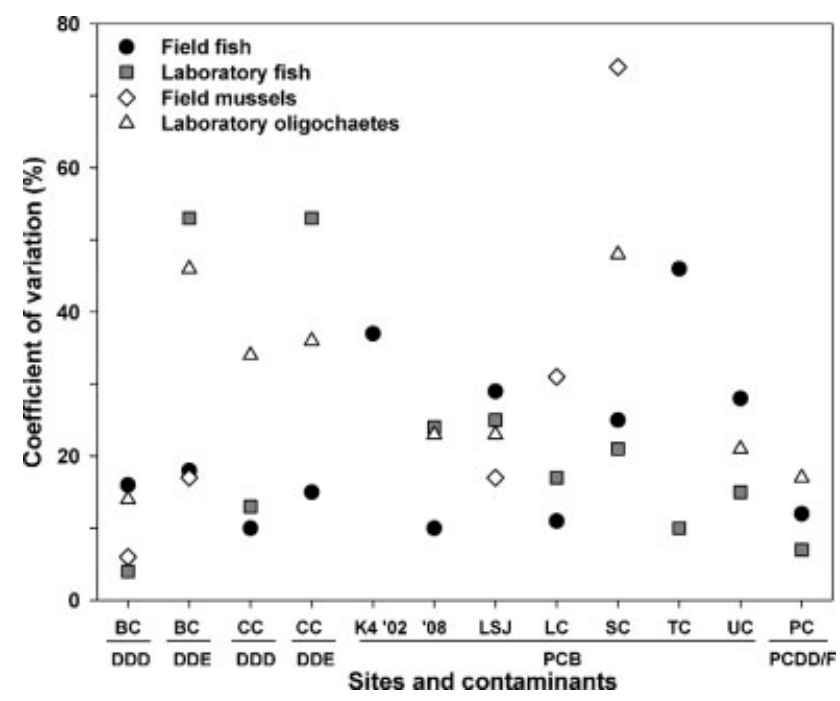

Fig. 5. Estimate of uncertainty of bioaccumulation between field- and laboratory-exposed organisms for various sites/contaminants of concern. Data are coefficients of variation (\%) of lipid-normalized tissue residues.

Coefficients of variation of lipid-normalized residues in tissues of fish were typically less than $30 \%$, which has been considered a reasonable level of biological variation in laboratory-based toxicity tests [20]. The exception to this was $C V$ s for tissue residues of DDE in laboratory fish $(53 \%$ for sites BC and CC) and PCBs in fish collected from sites K4 (2002; 37\%) and TC $(46 \%)$. Other than these incidents of higher $C V \mathrm{~s}$, the variability associated with the field and laboratory estimates in fish were fairly similar within each site. Slightly lower $C V$ s were frequently observed in the laboratory studies (except sites BC/CCDDE and K4 2008), likely as a result of the controlled conditions of rearing, testing, exposure time, and size of organism. Measurements of bioaccumulation in caged mussels at sites CC, $\mathrm{UC}$, and PC were based on one composite of organisms, in which case the uncertainty associated with these estimates could not be quantified. This further limits our discussion of the factors contributing to the disparity in bioaccumulation between mussels and oligochaetes exposed to sediment from sites $\mathrm{CC}$ and PC. In the case of site $\mathrm{SC}$, the $C V \mathrm{~s}$ were very high for estimates of bioaccumulation in field and laboratory invertebrates (74 and 48\%, respectively), which increases the uncertainty of the relative differences between these estimates. Although methods such as narrowing the size range of organisms used and normalizing concentrations of contaminants in tissue to lipid content can be used to minimize the variability associated with these estimates of bioaccumulation, biological variability often remains the greatest source of uncertainty, particularly in controlled studies.

Biota-sediment accumulation factors account for differences in exposure by comparing the bioaccumulation of a contaminant in an organism relative to the concentration in the sediment. The sources of uncertainty associated with this type of estimate include not only the biological variability but also the exposure concentration in the sediment. Sediment from field investigations is often collected with the caged mussels, and laboratory organisms are exposed in closed or semiclosed systems, allowing fairly precise estimates of exposure. Greater uncertainty is associated with field estimates of exposures for fish. Exposure is dependent on their mobility and the heterogeneity of contamination of the sediment within a site. Collection of young-of-the-year fish is somewhat opportunistic and limited to areas that are accessible by boat or for seining, and exposure of fish to contaminated sediment or food (i.e., benthos) may occur elsewhere in the system. Estimates of exposure could potentially be improved by integrating the range of sediment concentrations over the home range of the fish. This may be particularly important for those sites that have a heterogeneous distribution of sediment or lack features that restrict the movement of fish within the system. Although field- and laboratory-derived BSAFs for fish were generally in good agreement for many of the sites we compared, the uncertainty associated with the estimate of exposure in the field is another factor potentially contributing to the differences that we observed.

It is necessary to standardize the duration of exposure under laboratory conditions, but this cannot accurately represent the length of exposure of organisms collected from the field. A 28-d laboratory exposure has been suggested as a standard, because this typically results in tissue residues within $80 \%$ of steady state [10]. This test duration has been validated in a number of studies that found reasonable agreement between tissue residues of field-collected and laboratory-exposed organisms, including for most PCDD/F congeners [21-25]. This comparative approach assumes that organisms in both the laboratory and the field have reached steady-state concentrations. Kinetic studies under laboratory conditions have demonstrated that L. variegatus typically reach steady-state concentrations within $28 \mathrm{~d}[22,24,26]$. However, based on elimination rates of PCBs determined in situ for E. complanata by Raeside et al. [27], it is possible that the 21- or 28-d exposures used in the OMOE field studies do not reflect steady-state concentrations in mussels. Therefore, comparison of bioaccumulation between the field and the laboratory in the present study may be confounded by nonsteady-state concentrations in mussels versus steady-state concentrations in L. variegatus. If the measured concentrations in mussels in the present study are corrected to steady-state concentrations using the procedures of Raeside et al. [27], the disparity in BSAFs between these invertebrate species is typically reduced (data not shown). With these corrections, the laboratory BSAFs are, on average, only 2.8 times higher than those from the field ( 3.1 if data from site PC are included). Raeside et al. [27] observed that elimination rates varied considerably across their field sites, with maximal differences of 4.9- to 5.5-fold for more highly chlorinated PCB congeners. Therefore, although correction to steady-state concentrations appears to improve the comparability between these species, the uncertainty associated with this approach must be considered when extrapolating the relationships observed by Raeside et al. [27] to other field sites and compounds.

Uncertainty may exist with regard to whether tissue residues in fish also represent steady-state concentrations. Extremely few laboratory studies published in the literature have examined bioaccumulation in fish exposed to sediment. Although $28 \mathrm{~d}$ has also been recommended as the duration for bioconcentration tests with fish [28], it is uncertain whether this duration is sufficient for assessing steady-state in fish when sediment is the source of contaminants. Comparison of bioaccumulation between laboratory-exposed fish and to those from the field can validate this test duration, but this too relies on the assumption that fish collected in the field represent steady-state concentrations. Steady state in the field could be inferred from long-term exposure of the fish, but there is also great potential for growth dilution of contaminants. This may occur if the growth rate is much faster than the rate of contaminant uptake and if exposure is not continuous because of movement into or 
out of contaminated areas. Further assessment of how representative these laboratory and field measurements in fish are of steady-state tissue residues may improve the ability to make comparisons between these types of studies.

Differences between field and laboratory estimates of bioaccumulation, particularly for comparisons made years apart, could be due to changes in source of contamination. Although only total PCBs and PCDD/Fs were reported in the present study, the congener profiles were compared between past and recent samples of sediment. For the majority of the sites, the percentage contribution of individual congeners matched almost completely. This suggests that no additional sources of these contaminants existed and that environmental weathering has had a negligible impact on the congener patterns between the sampling periods. Differences in bioaccumulation between field and laboratory studies may also be due to species-specific accumulation of various congeners. Evidence for this in the three laboratory-exposed species was not observed for PCBs but was to a certain extent for PCDD/Fs [9]. Data from the field studies indicate that less chlorinated congeners had a higher contribution to total PCBs in mussels than in fish in some sites, and even slight differences for certain congeners were observed between different fish species within a site (data not shown). However, these differences were unlikely to influence the relative comparison of total PCB accumulation between field and laboratory organisms in the present study.

Finally, uncertainty also exists concerning comparison of BSAFs across studies. In the present study, these relative measures of bioaccumulation were used primarily to facilitate comparisons between different fish and invertebrate species across sediments with different concentrations of contaminants and organic carbon (i.e., within a site). This approach relies on the assumption that BSAFs are independent of chemical concentration, organic carbon content, or lipid content [16,17]. BSAFs have also been used to compare bioaccumulation across different species and sites, which is further based on the assumption that these factors are independent of species, type of sediment, organic carbon, and contaminant. The present study, and work by others, suggests that these assumptions are not always valid [5,9,16,29-32]. Indeed, it has been shown that different fractions of TOC, black carbon in particular, can enhance sorption and decrease bioavailability of contaminants, especially with planar compounds such as PAHs or PCDD/Fs [33-35]. However, BSAFs remains very useful for making these relative comparisons of bioaccumulation. To minimize the associated uncertainty, it is important to understand and identify any of the assumptions that are made with respect to these factors and to make comparisons that are appropriate.

\section{CONCLUSIONS}

In the present study comparing field and laboratory estimates of bioaccumulation, a priori considerations were necessary because of the temporal discontinuity of the studies. Our approach considered changes in site conditions, sediment concentrations, and contaminant patterns to compare tissue residues or BSAFs between field- and laboratory-exposed organisms. Despite this potential for temporal variability, good agreement was found between tissue residues in fish when concentrations in sediment were similar. For the majority of sites, BSAFs for field-collected and laboratory-exposed fish were usually within a factor of 2 . Biota-sediment accumulation factors for $L$. variegatus in the laboratory were typically greater (by a factor of 2-9) than those for mussels caged in the field, likely because of differences in the routes of exposure between these species. Overall, these laboratory methods generally overestimated the relative bioavailability of contaminants compared with field conditions by a factor of 1.1 to 9.2. Other than the great disparity observed for PCDD/Fs between field and laboratory studies, on average, the laboratory-derived BSAFs with $P$. promelas and $L$. variegatus overestimated those from field-collected fish and field-exposed mussels by factors of 1.6 and 3.6, respectively. These laboratory methods reflect a potentially worst-case exposure scenario and thereby provide a conservative estimate of bioaccumulation and bioavailability of contaminants.

The best answers with respect to laboratory and field comparisons of bioaccumulation are achieved on a case-by-case basis, because bioaccumulation is often site specific. Several factors might also contribute to the disparity between estimates and should be identified and considered in these comparisons. The present study indicates that the use of fish and invertebrates in the method allows the laboratory data to be validated best or field verified with the fish comparison, although both the invertebrate and the fish data can be used to fill data gaps for risk assessment and modeling the trophic transfer of contaminants. Evidence suggests that BSAFs are not always independent of contaminant concentration, species, or sediment type, so comparisons across (field or laboratory) studies using different organisms exposed to different sediments or conditions might not be a true reflection of bioaccumulation potential. This further supports the use of laboratory methods with standardized procedures and standard test species, which can be used to help address the issue of comparisons between sites and over time.

\section{SUPPLEMENTAL DATA}

Table S1. Field and laboratory assessments of bioaccumulation and sediment data from nine contaminated sites in Ontario. (3I KB XLS)

Figure S1. Contribution (\%) of PCB homologues in sediment and biota from 2006 field (F) and 2008 laboratory (L) studies for site SC. (40 KB DOC)

Acknowledgement-We thank E. Awad, N. Benoit, S. Clerk, R. Fletcher, T. Labencki, S. Petro, and L. Richman of the OMOE's Environmental Monitoring and Reporting Branch for providing the field data and site information. This work was supported by the Best in Science Program of the OMOE (projects 6703 and 89004).

\section{REFERENCES}

1. Franke C, Studinger G, Berger G, Bohling S, Bruckmann U, Cohorsfresenborg D, Johncke U. 1994. The assessment of bioaccumulation. Chemosphere 29:1501-1514.

2. Feijtel T, KloepperSams P, denHaan K, vanEgmond R, Comber M, Heusel R, Wierich P, TenBerge W, Gard A, deWolf W, Niessen H. 1997. Integration of bioaccumulation in an environmental risk assessment. Chemosphere 34:2337-2350.

3. Chapman PM, Anderson J. 2005. A decision-making framework for sediment contamination. Integr Environ Assess Manag 1:163-173.

4. Grapentine L, Anderson J, Boyd D, Burton GA, DeBarros C, Johnson G, Marvin C, Milani D, Painter S, Pascoe T, Reynoldson T, Richman L, Solomon K, Chapman PM. 2002. A decision making framework for sediment assessment developed for the Great Lakes. Hum Ecol Risk Assess 8:1641-1655.

5. Lee H. 1992. Models, muddles and mud: Predicting bioaccumulation of sediment-associated pollutants. In: Burton GA Jr, ed, Sediment Toxicity Assessment. Lewis, Boca Raton, FL, USA, pp 267-293.

6. U.S. Environmental Protection Agency. 2002. A Guidance Manual to Support the Assessment of Contaminated Sediments in Freshwater Ecosystems. EPA-905-B02-001-C. Chicago, IL. 
7. U.S. Environmental Protection Agency. 2000. Bioaccumulation Testing and Interpretation for the Purpose of Sediment Quality Assessment: Status and Needs. EPA 823-R- 00-001. Washington, DC.

8. American Society for Testing and Materials. 2002. Standard guide for conducting in-situ field bioassays with caged bivalves. E2122-02. In: Annual Book of ASTM Standards, Vol 11.05. West Conshohocken, PA

9. Van Geest JL, Poirier DG, Solomon KR, Sibley PK. 2011. A comparison of the bioaccumulation potential of three freshwater organisms exposed to sediment-associated contaminants under laboratory conditions. Environ Toxicol Chem 30:939-949 (this issue).

10. American Society for Testing and Materials. 2000. Standard guide for determination of the bioaccumulation of sediment-associated contaminants by benthic invertebrates. E1688-00a. In Annual Book of ASTM Standards, Vol 11.05, West Conshohocken, PA, pp 1077-1130.

11. U.S. Environmental Protection Agency. 2000. Methods for Measuring the Toxicity and Bioaccumulation of Sediment-associated Contaminants with Freshwater Invertebrates. EPA 600/R-99/064, 2nd ed. Duluth, MN.

12. Bedard D, Hayton A, Persaud D. 1992. Laboratory Sediment Biological Testing Protocol, Ontario Ministry of the Environment. Queen's Printer, Ontario, Canada.

13. Environment Canada. 1997. Biological Test Method: Test for Survival and Growth in Sediment Using the Freshwater Amphipod Hyalella azteca. EPS 1/RM/33. Environmental Protection Series. Ottawa, Ontario.

14. Environment Canada. 1997. Biological Test Method: Test for Survival and Growth in Sediment Using the Larvae of Freshwater Midges (Chironomus tentans or Chironomus riparius). EPS 1/RM/32. Environmental Protection Series. Ottawa, Ontario.

15. Van Geest JL, Poirier DG, Solomon KR, Sibley PK. 2010. The effect of organism density on the bioaccumulation of contaminants from sediment in three aquatic test species: A case for standardizing to sediment organic carbon. Arch Environ Contam Toxicol, DOI: 10.1007/s00244-0109573-7.

16. Lake JL, Rubinstein NI, Lee H II, Lake CA, Heltshe J, Pavignano S. 1990. Equilibrium partitioning and bioaccumulation of sediment-associated contaminants by infaunal organisms. Environ Toxicol Chem 9:10951106.

17. Di Toro DM, Zarba CS, Hansen DJ, Berry WJ, Swartz RC, Cowan CE, Pavlou SP, Allen HE, Thomas NA, Paqiun PR. 1991. Technical basis for establishing sediment quality criteria for nonionic organic chemicals using equilibrium partitioning. Environ Toxicol Chem 10:15411583 .

18. Maruya KA, Risebrough RW, Horne AJ. 1997. The bioaccumulation of polynuclear aromatic hydrocarbons by benthic invertebrates in an intertidal marsh. Environ Toxicol Chem 16:1087-1097.

19. Cretney WJ, Yunker MB. 2000. Concentration dependency of biotasediment accumulation factors for chlorinated dibenzo- $p$-dioxins and dibenzofurans in dungeness crab (Cancer magister) at marine pulp mill sites in British Columbia, Canada. Environ Toxicol Chem 19:3012_ 3023 .

20. Environment Canada. 2005. Guidance Document on Statistical Methods for Environmental Toxicity Tests. EPS 1/RM/46. Environmental Protection Series. Ottawa, Ontario.

21. Ankley GT, Cook PM, Carlson AR, Call DJ, Swenson JA, Corcoran HF, Hoke RA. 1992. Bioaccumulation of PCBs from sediments by oligochaetes and fishes: Comparison of lab and field studies. Can J Fish Aquat Sci 49:2080-2085.
22. Loonen H, Muir DCG, Parsons JR, Govers HAJ. 1997. Bioaccumulation of polychlorinated dibenzo- $p$-dioxins in sediment by oligochaetes: Influence of exposure pathway and contact time. Environ Toxicol Chem 16:1518-1525.

23. Brunson EL, T.J C, Dwyer FJ, Ingersoll CG, Kemble NE. 1998. Assessing the bioaccumulation of contaminants from sediments of the upper Mississippi River using field-collected oligochaetes and laboratory-exposed Lumbriculus variegatus. Arch Environ Contam Toxicol 35:191-201.

24. Ingersoll CG, Brunson EL, Wang N, Dwyer FJ, Ankley GT, Mount DR, Huckins J, Petty J, Landrum PF. 2003. Uptake and depuration of nonionic organic contaminants from sediment by the oligochaete Lumbriculus variegatus. Environ Toxicol Chem 22:872-885.

25. Lyytikäinen M, Rantalainen AL, Mikkelson P, Hamalainen H, Paasivirta J, Kukkonen JVK. 2003. Similarities in bioaccumulation patterns of polychlorinated dibenzo- $p$-dioxins and furans and polychlorinated diphenyl ethers in laboratory-exposed oligochaetes and semipermeable membrane devices and in field-collected chironomids. Environ Toxicol Chem 22:2405-2415.

26. Leppänen MT, Kukkonen JVK. 2004. Toxicokinetics of sedimentassociated polybrominated diphenylethers (flame retardants) in benthic invertebrates (Lumbriculus variegatus, Oligochaeta). Environ Toxicol Chem 23:166-172.

27. Raeside AA, O'Rourke SM, Drouillard KG. 2009. Determination of in situ polychlorinated biphenyl elimination rate coefficients in the freshwater myssel biomonitor Elliptio complanata deployed in the Huron-Erie corridor, southeast Michigan, USA, and southwest Ontario, Canada. Environ Toxicol Chem 28:434-445.

28. American Society for Testing and Materials. 2003. Standard guide for conducting bioconcentration tests with fishes and saltwater bivalve mollusks. E1022-94. In Annual Book of ASTM Standards. Vol 11.05 West Conshohocken, PA, pp 235-252.

29. Ferraro SP, Lee H II, Ozretich RJ, Specht DT. 1990. Predicting bioaccumulation potential; a test of a fugacity based model. Arch Environ Contam Toxicol 19:386-394.

30. Ferraro SP, Lee H II, Smith LM, Ozretich RJ, Specht DT. 1991. Accumulation factors for eleven polychlorinated biphenyl congeners Bull Environ Contam Toxicol 46:276-283.

31. Means JC, McElroy AE. 1997. Bioaccumulation of tetrachlorobiphenyl and hexachlorobiphenyl congeners by Yoldia limatula and Nephtys incisa from bedded sediments: Effects of sediment- and animal-related parameters. Environ Toxicol Chem 16:1277-1286.

32. Wong CS, Capel PD, Nowell LH. 2001. National-scale, field-based evaluation of the biota-sediment accumulation factor model. Environ Sc Technol 35:1709-1715.

33. Cornelissen G, Gustafsson O. 2005. Prediction of large variation in biota to sediment accumulation factors due to concentration-dependent black carbon adsorption of planar hydrophobic organic compounds. Environ Toxicol Chem 24:495-498.

34. Kukkonen JVK, Mitra S, Landrum PF, Gossiaux DC, Gunnarsson J, Weston DP. 2005. The contrasting roles of sedimentary plant-derived carbon and black carbon on sediment-spiked hydrophobic organic contaminant bioavailability to Diporeia species and Lumbriculus variegatus. Environ Toxicol Chem 24:877-885.

35. Cornelissen G, Cousins IT, Wiberg K, Tysklind M, Holmstrom H, Broman D. 2008. Black carbon-dominated PCDD/Fs sorption to soils at a former wood impregnation site. Chemosphere 72:1455-1461. 